\title{
YOGA THE STRESS RELIEVER: A BOON TO PERIODONTAL HEALTH
}

\author{
SURESH. D. $\mathrm{K}^{1} \&$ SHIVANI ABROL ${ }^{2}$ \\ ${ }^{I}$ HOD, Department of Periodontics, Seema Dental College, Uttarakhand, India \\ ${ }^{2}$ Postgraduate, Department of Periodontics, Seema Dental College, Uttarakhand, India
}

AIM \& OBJECTIVE: To compare stress levels, oral hygiene habits and periodontal status in subjects practicing yoga.

METHOD: The exposure of interest is the stress level of the patient. 30 subjects were evaluated. Subjects were divided into four groups based on their yoga duration: $>15,10-15,5-10$ and $<5$ years. Periodontal status of the individuals was evaluated using clinical parameters.

RESULTS: Comparison of the stress scale using one way ANOVA shows that mean value of $>15$ years is highest (54.25) followed by 10-15 years (44.25), 5-10 years (38) and least in < 5 years (31.38). Post hoc test showed better periodontal health in the yoga group (>15 years,10-15 years, 5-10 years, <5 years) $(p<0.001)$ (in all the four domains).
\end{abstract}

CONCLUSIONS: Lifestyle modification with yoga practice may benefit the individuals with risk factor in overall maintanence of periodontal health.

KEYWORDS: Stress, Periodontal Status \&Yoga

Received: Nov 23, 2018; Accepted: Dec 13, 2018; Published: Mar 26, 2019; Paper Id.: IJDRDJUN20193

\section{INTRODUCTION}

Periodontal disease is a highly prevalent inflammatory disease that involves the periodontium. Many factors including the host, pathogen and environmental factors are associated with the incidence and exacerabation of periodontal disease. ${ }^{1}$ Risk assessment has become increasingly important in the prevention of chronic diseases and has recently been applied to oral diseases. Consequently, a new paradigm is emerging to control the dental disease which involves identification and targeting high-risk individuals and intercepting the disease process. ${ }^{2}$ Thus identification of major modifiable risk factor is needed. ${ }^{3}$ Lifestyle is frequently considered a consciously chosen personal behavior. Lifestyle may be considered as an expression of the social and cultural circumstances that condition and constrain action, in addition to the personal decisions the individual may make. Psychological stress, particularly if sustained over an extended period of time, can have deleterious effects on the body, representing an important example of the mind-body interaction. The role of stress on systemic health has been well known for decades. Similarly, the role of psychological factors in periodontal disease has a significant history. Currently, stress is classified as a risk indicator for periodontal disease. ${ }^{4}$ Earlier studies showed that psychosocial stress, physiological stress, anxiety, and depression were associated with a significant amount of periodontal disease progression and wound healing. Hans Selye (1946) coined the term stress and postulated the possible mechanism of activation of the adrenocortico-pituitary axis. The stress-induced responses either result in a change in behavior or transmitted to the hypothalamic-pituitary-adrenal (HPA) axis to release corticotrophic- 
releasing hormone (CRH) from the hypothalamus. CRH activates the pituitary gland to release adrenocorticotropic hormone $(\mathrm{ACTH})$, which in turn induces the release of glucocorticosteroids like cortisol from the adrenal cortex.

Cortisol (the primary glucocorticoid) reduces the number of circulating lymphocytes, monocytes, and other proinflammatory cells resulting in a decrease in functions such as chemotaxis and proliferation of effector lymphocytes to differentiate into helper lymphocytes, cytotoxic lymphocytes, natural killer cells, $\operatorname{IgG}$ and $\operatorname{IgA}$ antibody-forming B cells. Decreased functioning of neutrophils and secretory IgA and IgG antibodies leads to increased susceptibility to periodontal infections, which results in increased production of inflammatory cytokines like IL-1 and matrix metalloproteinases by the periodontal pathogens causing rapid periodontal tissue destruction. ${ }^{5}$

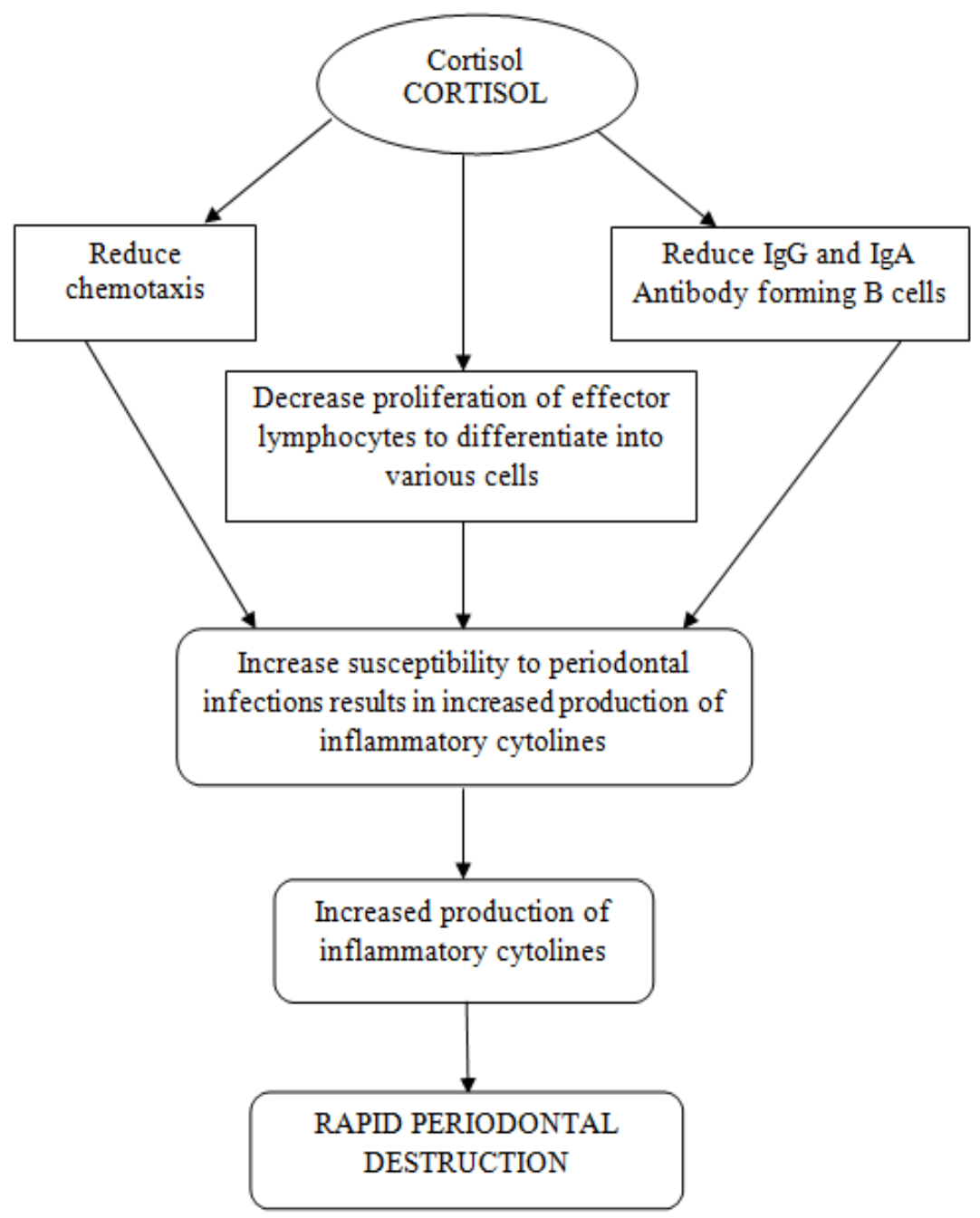

Figure 1

Increase in stressful conditions and life-style diseases have led to the popularization of yoga and meditation in the western world. This has resulted in the fusion of western science with that of the eastern philosophy.

Yoga is one of the major contributions of ancient Indians to the philosophy of life and has been practiced in ancient India by the followers of Jainism, Buddhism, Shaivism and several other ascetic traditions. It was Patanjali (200 B.C) who integrated yoga into the Vedic religion through a compilation of Yoga sutras. ${ }^{6}$ The word yoga is derived from the Sanskrit word "yuj" which means union, yoke, or to join and to direct and concentrate one's attention. Regular 
practice of yoga helps to build better connectivity between the mind and body through a series of postures, breathing exercises, and meditation. Pratyahara is the fifth of Patanjali's eight-limbed path of yoga. It can be an important tool for stress reduction, which can help in almost instant stress reduction by lengthening the exhalation relative to the inhalation, which in turn increases the tone in the sympathetic nervous system. The benefits of yoga include decreased stress and tension, increased strength, balance, and flexibility of muscles, lowered blood pressure, and reduction in cortisol levels. ${ }^{5}$

Although present research strongly supports the association of various forms of stress with periodontal disease, this pilot, cross-sectional study was done mainly to compare stress levels, oral hygiene habits and periodontal status in individuals practicing yoga.

\section{MATERIALS AND METHODS}

The exposure of interest is the stress level of the patient. A total of 30 individuals those practicing yoga were chosen to participate in the study. Subjects were divided into four groups based on their yoga duration $>15$ years, 10-15 years, 5-10 years, <5 years. These volunteers were recruited from the yoga center in Rishikesh, Uttarakhand.

A questionnaire developed for the study included general information: age, gender, years practicing yoga. A questionnaire regarding their oral hygiene habits like Tooth-brushing Technique, Frequency Of Tooth-brushing, Type of Toothbrush Used, Time Spent For Oral Care Frequent Use Of Mouthwash, Interdental Cleaning Habit. Oral examination recorded following periodontal parameters: Plaque Index( Silness and Loe 1964), Modified Gingival Index (Lobene and Wetherford 1986), Bleeding On Probing, Probing Pocket Depth. William's periodontal probe with $1 \mathrm{~mm}$ precision was used for calculating PPD. For Psychological evaluation, Ardell Wellness Stress Test was used.

\section{STATISTICALANALYSIS}

All obtained data between 4 groups were analyzed by using One-way ANOVA test. Posthoc Tukey's was used for subgroup analysis. The p-value less than 0.001 were considered statistically highly significant.

\section{RESULTS}

With the total of 30 patients included in the study and the patients were divided into 4 groups according to yoga practicing years i.e $>15$ years, $10-15$ years, 5-10 years, $<5$ years.

Mean values for all the parameters were calculated and intergroup comparisons were made using one-way ANOVA followed by multiple pair wise comparisons using Tukey's posthoc test among the groups

Table 1: Comparison of Mean Values of Clinical Parameters using One-Way ANOVA

\begin{tabular}{|c|c|c|c|c|c|c|c|}
\hline & & $\mathbf{N}$ & Mean & Std. \pm Deviation & $\begin{array}{c}\text { Mean } \\
\text { Squares }\end{array}$ & $\mathbf{f}$ & $p$ value \\
\hline \multirow{5}{*}{ Stress scale } & $>15$ years & 4 & 54.25 & \pm 2.217 & \multirow{5}{*}{530.581} & \multirow{5}{*}{18.39} & \multirow{5}{*}{$\leq 0.001$} \\
\hline & 10-15 years & 8 & 44.25 & \pm 5.392 & & & \\
\hline & $5-10$ years & 10 & 38 & \pm 6.912 & & & \\
\hline & $<5$ years & 8 & 31.38 & \pm 3.815 & & & \\
\hline & Total & 30 & 40.07 & \pm 8.986 & & & \\
\hline \multirow{5}{*}{ Plaque index } & $>15$ years & 4 & 0 & 0 & \multirow{5}{*}{1.564} & \multirow{5}{*}{24.48} & \multirow{5}{*}{$\leq 0.001$} \\
\hline & 10-15 years & 8 & 0.3375 & \pm 0.28253 & & & \\
\hline & 5-10 years & 10 & 0.76 & \pm 0.22211 & & & \\
\hline & $<5$ years & 8 & 1.1625 & \pm 0.30677 & & & \\
\hline & Total & 30 & 0.6533 & \pm 0.46811 & & & \\
\hline
\end{tabular}




\begin{tabular}{|c|c|c|c|c|c|c|c|}
\hline \multicolumn{8}{|c|}{ Table 1: Contd., } \\
\hline \multirow{5}{*}{ Modified gingival index } & $>15$ years & 4 & 0 & 0 & \multirow{5}{*}{2.306} & \multirow{5}{*}{15.985} & \multirow{5}{*}{$\leq 0.001$} \\
\hline & $10-15$ years & 8 & 0.125 & \pm 0.35355 & & & \\
\hline & $5-10$ years & 10 & 1 & \pm 0.4714 & & & \\
\hline & $<5$ years & 8 & 1.125 & \pm 0.35355 & & & \\
\hline & Total & 30 & 0.6667 & \pm 0.60648 & & & \\
\hline \multirow{5}{*}{ Bleeding on probing } & $>15$ years & 4 & 0 & 0 & \multirow{5}{*}{0.275} & \multirow{5}{*}{1.799} & \multirow{5}{*}{0.172} \\
\hline & $10-15$ years & 8 & 0 & 0 & & & \\
\hline & $5-10$ years & 10 & 0.3 & \pm 0.48305 & & & \\
\hline & $<5$ years & 8 & 0.375 & \pm 0.51755 & & & \\
\hline & Total & 30 & 0.2 & \pm 0.40684 & & & \\
\hline \multirow{5}{*}{ Probing pocket depth } & $>15$ years & 4 & 1 & 0 & \multirow{5}{*}{3.975} & \multirow{5}{*}{11.645} & \multirow{5}{*}{$\leq 0.001$} \\
\hline & $10-15$ years & 8 & 1.75 & \pm 0.70711 & & & \\
\hline & $5-10$ years & 10 & 2.5 & \pm 0.52705 & & & \\
\hline & $<5$ years & 8 & 2.875 & \pm 0.64087 & & & \\
\hline & Total & 30 & 2.2 & \pm 0.8469 & & & \\
\hline
\end{tabular}

Table 1: Comparison of Yoga duration, stress scale, PI, MGI, PPD using one way ANOVA test shows that the mean value of $>15$ years is highest followed by $10-15$ years, 5-10 years least in $<5$ years. This difference is statistically Significant with a test value of 18.39 and p-value of <0.001. Comparison of bleeding on probing using one way ANOVA test shows that the mean value of $<5$ years $(0.375)$ is highest followed by $5-10$ years $(0.3),>15$ years $(0)$ least in $>15$ years(0). This difference is statistically Not Significant with a test value of 1.799 and p-value of 0.172 .

Table 2: Multiple Comparison of Clinical Parameters by Using Tukey's post-hoc Test

\begin{tabular}{|c|c|c|c|c|}
\hline $\begin{array}{c}\text { Dependent } \\
\text { Variable }\end{array}$ & $\begin{array}{c}\text { Comparison } \\
\text { Group }\end{array}$ & Compared With & Mean Difference & P Value \\
\hline \multirow{6}{*}{ Stress scale } & \multirow{3}{*}{$>15$ years } & 10-15 years & $10.000 *$ & $\underline{\underline{0.026}}$ \\
\hline & & 5-10 years & $16.250 *$ & $\leq 0.001$ \\
\hline & & $<5$ years & $22.875^{*}$ & $\leq 0.001$ \\
\hline & \multirow{2}{*}{$10-15$ years } & $5-10$ years & 6.25 & 0.092 \\
\hline & & $<5$ years & $12.875^{*}$ & $\leq 0.001$ \\
\hline & 5-10 years & $<5$ years & 6.625 & 0.068 \\
\hline \multirow{6}{*}{ Plaque index } & \multirow{3}{*}{$>15$ years } & 10-15 years & -0.3375 & 0.155 \\
\hline & & $5-10$ years & $-.76000^{*}$ & $\leq 0.001$ \\
\hline & & $<5$ years & $-1.16250^{*}$ & $\leq 0.001$ \\
\hline & \multirow{2}{*}{$10-15$ years } & 5-10 years & $-.42250 *$ & 0.008 \\
\hline & & $<5$ years & $-.82500^{*}$ & $\leq 0.001$ \\
\hline & $5-10$ years & $<5$ years & $-.40250 *$ & 0.012 \\
\hline \multirow{6}{*}{$\begin{array}{l}\text { Modified gingival } \\
\text { index }\end{array}$} & \multirow{3}{*}{$>15$ years } & 10-15 years & -0.125 & $\overline{0.949}$ \\
\hline & & 5-10 years & $-1.00000^{*}$ & $\underline{0.001}$ \\
\hline & & $<5$ years & $-1.12500^{*}$ & $\leq 0.001$ \\
\hline & \multirow{2}{*}{$10-15$ years } & $5-10$ years & $-.87500 *$ & $\leq 0.001$ \\
\hline & & $<5$ years & $-1.00000^{*}$ & $\leq 0.001$ \\
\hline & $5-10$ years & $<5$ years & -0.125 & 0.898 \\
\hline \multirow{6}{*}{$\begin{array}{l}\text { Bleeding on } \\
\text { probing }\end{array}$} & \multirow{3}{*}{$>15$ years } & 10-15 years & 0 & 1 \\
\hline & & 5-10 years & -0.3 & 0.573 \\
\hline & & $<5$ years & -0.375 & 0.415 \\
\hline & \multirow{2}{*}{$10-15$ years } & $5-10$ years & -0.3 & 0.387 \\
\hline & & $<5$ years & -0.375 & 0.245 \\
\hline & 5-10 years & $<5$ years & -0.075 & 0.977 \\
\hline \multirow{4}{*}{$\begin{array}{l}\text { Probing pocket } \\
\text { depth }\end{array}$} & \multirow{3}{*}{$>15$ years } & $10-15$ years & -0.75 & 0.181 \\
\hline & & 5-10 years & $-1.50000^{*}$ & $\underline{\underline{0.001}}$ \\
\hline & & $<5$ years & $-1.87500^{*}$ & $\leq 0.001$ \\
\hline & 10-15 years & 5-10 years & -0.75 & 0.054 \\
\hline
\end{tabular}




\begin{tabular}{|c|c|c|c|c|}
\hline & & $<5$ years & $-1.12500 *$ & $\underline{0.004}$ \\
\hline & $5-10$ years & $<5$ years & -0.375 & $\overline{0.539}$ \\
\hline \multirow{6}{*}{ Yoga duration since } & \multirow{3}{*}{$>15$ years } & $10-15$ years & $6.375^{*}$ & $\leq 0.001$ \\
\hline & & $5-10$ years & $10.300 *$ & $\overline{<0.001}$ \\
\hline & & $<5$ years & $15.250 *$ & $\leq 0.001$ \\
\hline & \multirow{2}{*}{ 10-15 years } & $5-10$ years & $3.925 *$ & $\leq 0.001$ \\
\hline & & $<5$ years & $8.875^{*}$ & $\leq 0.001$ \\
\hline & 5-10 years & $<5$ years & $4.950 *$ & $\leq 0.001$ \\
\hline
\end{tabular}

Table 2: Comparison of stress scale using Post hoc Tukey test shows that The difference between 10-15 years and 5-10 years is NOT statistically significant with a mean difference of 6.25 and p-value of 0.092 . comparison of PI shows The difference between $>15$ years and 10-15 years is NOT statistically significant with a mean difference of -0.3375 and p-value of 0.155. comparison of MGI shows that The difference between $>15$ years and 10-15 years is NOT statistically significant with a mean difference of -0.125 and p value of 0.949 . BOP scores shows no significant differences between the groups. Comparison of yoga duration since shows highly significant differences between the groups.

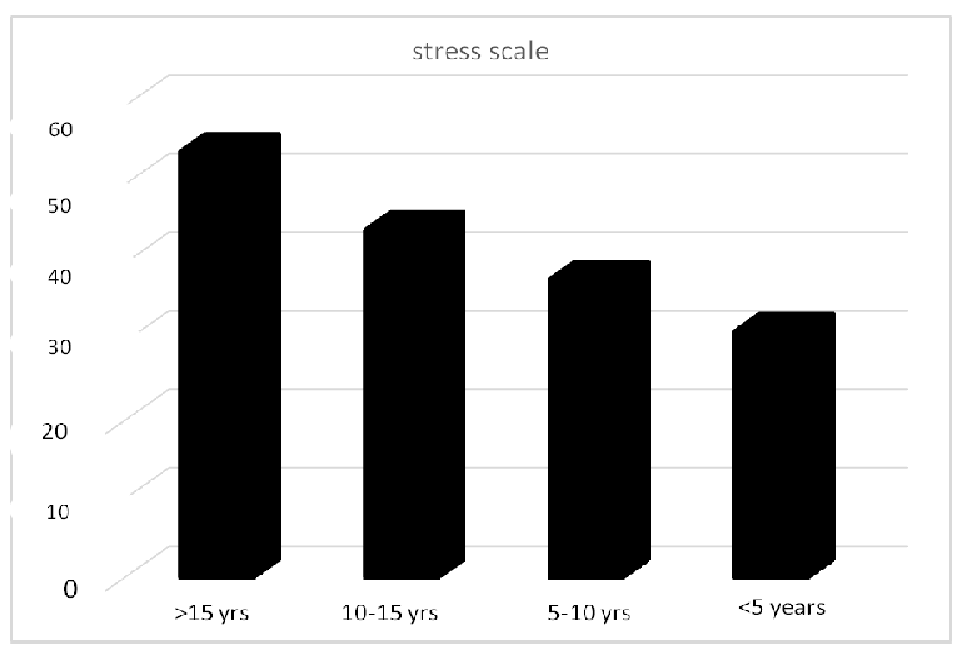

Figure 2

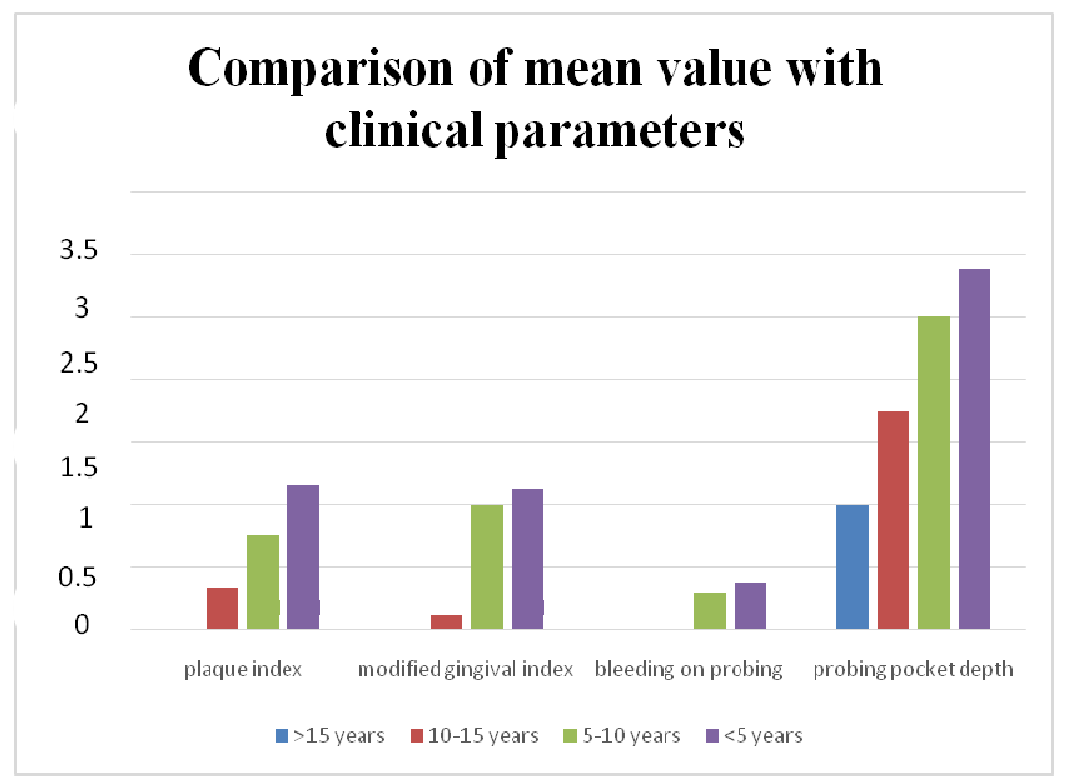

Figure 3 


\section{DISCUSSIONS}

The role of psychosocial disturbances in the etiology of the periodontal disease was proposed by Burstone, Miller, Firestone et al. in the early literature. ${ }^{6}$ According to Miller and Firestone, ${ }^{7}$ Moulton et al. ${ }^{8}$ and Belting and Gupta, 1961, ${ }^{9}$ psychological disturbances can lead patients to neglect oral hygiene, resulting in greater amounts of plaque accumulation, which is detrimental to the periodontal tissues. Moulton et al. reported that severe cases of acute necrotizing ulcerative gingivitis (ANUG) were preceded by acute anxiety. ${ }^{8}$ Yoga has become increasingly popular in western cultures as a means of exercise and training fitness (Raub J A, 2002). One of the main goals of yoga is to achieve tranquility of the mind and create a sense of well being, feeling of relaxation, improve efficiency and self-confidence, increase attentiveness and lower irritability, and create an optimistic outlook to life (Arora S et al., 2008). Practicing yoga and meditation is a means to manage and relieve both acute and chronic stress, help individuals overcome co-morbidities associated with disease and lead to enhanced quality of life (Oken B S et al., 2006).

Studies have shown that asanas, meditation or a combination of the two can reduce pain and disability while improving flexibility and functional mobility in people with numerous conditions causing chronic pain (Mc Call T, 2007). ${ }^{6}$ Kishor kumar katuri et al showed that individuals practicing yoga regularly had low serum cortisol levels, HAM-A scale and ZSDS scores, and better periodontal health. ${ }^{5}$

Catherine Woodyard in 2011 explore the therapeutic effects of yoga and its ability to increase the quality of life and showed that yoga reduces stress, anxiety and improve sleep patterns, enhances overall well-being and quality of life.

Observations on oral hygiene practices and clinical parameters showed that those who properly maintain oral hygiene, theirperiodontiumwereinbettercondition. ${ }^{10}$ Mangesh A. Banker et al in 2013 showed that addition of regular Yoga exercises in the daily routine of elderly people can help to achieve good quality of life and better oral hygiene. ${ }^{11}$ This view is further supported by Mohammad S. Al-Zahrani et al who stated that an increased number of health-enhancing behaviors like practicicing yoga is associated with a lower periodontitis prevalence. ${ }^{3}$

In the present study, stress levels were assessed to find the existing relationship between stress and periodontitis by comparing with yoga practicing individuals. In this cross-sectional study, all the included subjects were evaluated for their stress levels with the help of a questionnaire and the periodontal health status assessed. Plaque level, bleeding on probing, probing depth was higher in those subjects who practicing yoga for less than 5 years. Those who practicing yoga for more than 15 years have low plaque level, less bleeding on probing, less pocket depth. This is in agreement with previous studies by Rosania et al., ${ }^{12}$ Johannsen et al. ${ }^{13}$ and Klages et al. ${ }^{14}$ According to Deinzer et al., students who are under academic stress show high plaque values as well as severe gingival inflammation. ${ }^{15}$ High plaque values in group I subjects may be due to infrequent or inefficient tooth brushing of these individuals. Similar to the previous studies, it was noticed that stress may interfere with tooth brushing and plaque control measures. ${ }^{16}$

The present study, observation of stress scale shows that those who practicing yoga since longer duration, they have experienced less stress and their value on stress scale is highest.

\section{CONCLUSIONS}

Development in medical technology has resulted in the close observation of brain and psychological states and thus identifying the subtle changes taking place with the practice of yoga and meditation. Some positions like the sun salutation and abdominal breathing result in the activation of the sympathetic nervous system whereas slow asanas and 
meditation stimulate the parasympathetic nervous system. Yoga practice may help to improve systemic health, reduced depression and anxiety, and cause better-wound healing, and might have therapeutic benefits in the severity or progression of periodontal diseases like other chronic inflammatory diseases which are influenced by various risk factors such as stress. As mind-body fitness programs such as yoga continue to increase, it is important for healthcare professionals to inform about the nature of yoga and its therapeutic effects. Individuals with lifestyle modification through the inclusion of yoga in their daily routine may benefit the overall health of the individuals along with preventing the risk of developing periodontal disease.

The association of yoga, stress and periodontal disease will require further extensive studies to understand the benefits of yoga in stress relief, as well as its benefits in the control of periodontal disease progression and maintenance.

\section{REFERENCES}

1. Shimazaki Y et al. Relationship Between Obesity and Physical Fitness and Periodontitis. J Periodontol 2010;81:1124-1131.

2. Grossi $S$ G et al. Assessment of Risk for Periodontal Disease. I. Risk Indicators for attachment Loss. J Periodontol 1994;65:260-267.

3. Al-Zahrani M, S Borawski E A, and Bissada N F. Periodontitis and Three Health-Enhancing Behaviors: Maintaining Normal Weight, Engaging in Recommended Level of Exercise, and Consuming a High-Quality Diet. J Periodontol 2005;76:13621366.

4. Katuri $K K$ et al. Association of yoga practice and serum cortisol levels in chronic periodontitis patients with stress-related anxiety and depression I Int. Soc Prev Community Dent 2016; 6 : 7-14.

5. Khalaf, S. K., Al-Asadi, J. N., \& Abed, A. H. (2014). Knowledge and attitudes towards patient's rights among health care providers in primary care health centers in Basrah. Int J Med Pharmaceut Sci, 4, 7-14.

6. www.nysut.org/ /media/files/nysut/.../2013/.../socialservices_stressassessments

7. Genco RJ et al. Models to evaluate the role of stress in periodontal disease. Ann Periodontol. 1998;3:288-302.

8. Miller SC, Firestone JM. Psychosomatic factors in the etiology of periodontal disease; a critical review of the literature. Oral Surg Oral Med Oral Pathol. 1947;33:675-86.

9. Moulton R, Ewen S, Thieman W. Emotional factors in periodontal disease. Oral Surg Oral Med Oral Pathol. 1952;5:833-60.

10. Belting CM, Gupta OP. The influence of psychiatric disturbances on the severity of periodontal disease. $J$ Periodontol. 1961;32:219-26.

11. Catherine Woodyard Exploring the therapeutic effects of yoga and its ability to a increase quality of life Int J Yoga 2011; $4: 49-54$

12. Al Maghrabi, K. (2014). The pattern of skin diseases among patients attending primary health care centers in Jeddah city, Saudi Arabia, 2012. International Journal of Research in Applied, Natural and Social Sciences.

13. Mangesh A.Banker, Sarika K. Chaudhary, Kiran D. Chaudhary Impact of long term Yoga practice on sleep quality and quality of life in the elderly J Ayurveda Integr Med.2013;4: 28-32

14. Rosania AE, Low KG, McCormick CM, Rosania DA. Stress, depression, cortisol and periodontal disease. J Periodontol. 2009;80:260-6. 
15. Johannsen A, Asberg M, Söder PO, Söder B. Anxiety, gingival inflammation and periodontal disease in non-smokers and smokers-an epidemiological study. J Clin Peridontol. 2005;32:488-91.

16. Klages $U$, Weber AG, Wehrbein H. Approximal plaque and gingival sulcus bleeding in routine dental care patients: Relations to life stress, somatization and depression. J Clin Periodontol. 2005;32:575-82.

17. Deinzer R, Hilpert D, Bach K, Schawacht M, Herforth A. Effects of academic stress on oral hygiene--a potential link between stress and plaque-associated disease? J Clin Periodontol. 2001;28:459-64.

18. Jalaludin, J., Nordiyana, M. S., \& Suhaimi, N. F. (2014). Exposure to indoor air pollutants (formaldehyde, VOCs, ultrafine particles) and respiratory health symptoms among office workers in old and new buildings in Universiti Putra Malaysia. International Journal of Applied and Natural Sciences, 3(1), 69-80.

19. Abegg C, Croucher R, Marcenes WS, Sheiham A. How do routines of daily activities and flexibility of daily activities affect tooth-cleaning behaviour? J Public Health Dent. 2000;60:154-8. 